\title{
Fingertip rapid point-of-care test in adult case-finding in coeliac disease
}

\author{
Alina Popp ${ }^{1,2,4^{*}}$, Mariana Jinga ${ }^{1,3}$, Ciprian Jurcut $^{3}$, Vasile Balaban ${ }^{3}$, Catalina Bardas ${ }^{2}$, Kaija Laurila $^{4}$, Florina Vasilescu ${ }^{3}$, \\ Adina Ene ${ }^{2}$, loana Anca ${ }^{1,2}$ and Markku Mäki ${ }^{4}$
}

\begin{abstract}
Background: Coeliac disease (CD), due to its protean clinical manifestation, is still very under diagnosed in adults and delays in diagnosis may take years and even decades. Simple tools to find cases in primary care may help to identify patients for further diagnostic tests. We have evaluated the usefulness of an on site rapid fingertip whole blood point-of-care test (POCT) for such a purpose.

Methods: As CD is known to run within families, we tested 148 healthy relatives of 70 Romanian index cases with biopsy-proven CD (87\% of all first-degree family members, median age 36 years) for the presence of circulating autoantibodies. In addition to performing the POCT (which measures blood erythrocyte self-TG2-autoantibody complexes) on site, blood was drawn for later evaluations of serum IgA-class endomysial antibodies (EMA). EMA-positive sera were further tested for transglutaminase 2 antibodies (TG2-lgA). All serological parameters were analyzed blindly in a centralized laboratory that had no knowledge of the on site POCT result. Endoscopic small intestinal biopsies was recommended for all POCT- or EMA-test positive subjects.
\end{abstract}

Results: In on site testing the POCT was positive in 12/148 first-degree relatives (8\%) and all these subjects were also serum EMA-positive. A positive EMA test was found only in one other subject. All remaining 135 healthy first-degree relatives were negative for both POCT and EMA. Four subjects positive for both POCT and EMA were negative for TG2-IgA. Ten out of thirteen of the antibody-positive subjects agreed to undergo endoscopy. The POCT was found to be positive in 8/9 first-degree relatives having coeliac-type mucosal lesions of grade Marsh $2(n=3)$ or Marsh $3(n=6)$. The three POCT-positive subjects not agreeing to undergo endoscopy were also both EMA- and TG2-IgA-positive.

Conclusion: The fingertip whole blood rapid POCT might fulfill the unmet need for a simple and cheap case-finding biomarker for early detection and presumptive diagnosis of CD. Confirmatory studies are warranted in adult case-finding in specialized outpatient clinics and in primary care.

Keywords: Coeliac disease, Healthy relatives, Case-finding, Point-of-care test

\section{Background}

Coeliac disease (CD) is a systemic disorder triggered by the ingestion of gluten, a protein present in wheat, rye and barley. Gluten injures the small intestinal mucosal lining leading to villous atrophy and crypt hyperplasia [1]. Individuals affected by the disease also share the autoimmune extended human leukocyte antigen (HLA) haplotypes DR3-DQ2, DR11/7-DQ2 or DR4-DQ8. The

\footnotetext{
* Correspondence: alina.popp@uta.fi

"University of Medicine and Pharmacy "Carol Davila", Str. Dionisie Lupu nr. 37, sector 1, 020022 Bucharest, Romania

${ }^{2}$ Institute for Mother and Child Care "Alfred Rusescu", Bdv. Lacul Tei nr. 120, sector 2, 020395 Bucharest, Romania

Full list of author information is available at the end of the article
}

prevalence of $\mathrm{CD}$ in various populations is around $1 \%$ $[2,3]$ but there are countries with lower and higher prevalence [4]. There is also evidence that the disease itself is increasing over time, similar to other autoimmune diseases in general [5-8]. CD manifests at all ages. It may be clinically silent, patients may show only vague symptoms or present with extraintestinal problems including psychiatric, neurologic, bone, liver or reproductive disorders or as malignancy [9-12].

It is well known that $\mathrm{CD}$ runs within families, and first-degree relatives of patients are at risk of developing the disorder [13-15]. By reason of the protean manifestation of $\mathrm{CD}$, clinical suspicion is not obvious, and it is

\section{Biomed Central}


clear that this disorder is highly under diagnosed worldwide $[1,4,7,16]$. Even if health professionals are aware of diagnostic delays, this period of latency persists and is counted in years and decades [17-19]. Screen-detected patients with clinically silent disease but manifest smallintestinal mucosal lesion seem to benefit from a glutenfree diet [20-22]. It has in fact been claimed that CD detected by screening is not silent but simply unrecognized [23]. Also new CD management models include firstdegree relatives as a high-risk group and recommend case-finding screening within families [24].

Active case-finding in primary care using sensitive and specific biomarkers of $\mathrm{CD}$ might be a solution to shorten diagnostic delays. Centralized laboratories provide autoantibody tests such as endomysial (EMA) and antitransglutaminase 2 (TG2) IgA antibody tests $[25,26]$. However, centralized laboratory tests are not easily available or affordable for medical health care in many parts of the world. An easy-to-use on site whole blood self-TG2-based fingertip point-of-care test (POCT) has been shown to be effective in $C D$ case finding in schoolchildren at a population-based level and in children with type 1 diabetes [21,27]. The POCT proved to be highly sensitive and specific resulting in an accuracy of $>95 \%$ to detect untreated CD [28]. Also, a recent evidence report showed the POCT to have a high pooled sensitivity and specificity in case finding of CD [26]. We hypothesize that a less invasive and less expensive POCT biomarker is able to pick out clinically silent $\mathrm{CD}$ in adults in a low-prevalence population. To test this hypothesis we chose to study $\mathrm{CD}$ families where the disease would be expected to be prevalent among first-degree relatives.

\section{Methods}

\section{Patients}

170 first-degree healthy relatives of 70 index cases (77 children and 15 adults) were invited over a five years period (2007-2012) to be evaluated for the presence of coeliac-autoantibodies. The inclusion criterion for the index cases was biopsy-proven CD (Marsh 3 mucosal lesion). Of the 170 subjects, 148 (18 children, 130 adults; median age 36 years, range 1.2-77) agreed to participate. The remaining 22 could not been reached or declined. At the time of the evaluation, all participants confirmed that they were consuming a regular gluten-containing diet.

\section{Whole blood and serum case-finding biomarkers}

The screening for the presence of $\mathrm{CD}$ autoantibodies in the healthy relatives took place on the same day as the diagnostic examinations of the index patients or in certain cases later, during regular follow-up visits. All centralized laboratory serologic determinations were made in blinded fashion without knowledge of the on-site fingertip whole blood POCT results.
The Biocard Celiac Test, AniBiotech, Vantaa, Finland, was selected as the point-of-care biomarker test for $C D$ case-finding. This rapid whole blood self TG2-based IgA-class fingertip test uses the patient's own endogenous TG2 found in the erythrocytes of a whole blood sample. When the finger-tip blood is haemolyzed, the liberated TG2 forms a complex with circulating autoantibodies, if present in the same sample. Blood erythrocyte selfTG2-autoantibody complexes are captured from the haemolyzed sample by TG2-binding proteins onto a solid phase and the presence of autoantibodies is measured by labeled antihuman IgA [28]. The results of the POCT were evaluated visually on site after five minutes, but no later than ten minutes, according to the manufacturer's recommendations (line visible in test window - positive result; no line in test window negative result).

On the same day when the POCT was performed, venous blood was drawn for laboratory serum autoantibody measurements. Serum IgA-class antiendomysial antibodies (EMA) were determined using an indirect immunofluorescence method (Nova Lite, Inova Diagnostics, CA, USA) with cut-off for positivity at a serum dilution of 1:5. Further serum dilutions (1:50, 1:100, $1: 200,1: 500,1: 1000,1: 2000,1: 4000)$ were made for initial positive samples till the highest positive titer was obtained for each sample. In the present series, no cases of selective IgA deficiency were found.

Serum samples showing positivity in the EMA test were further evaluated for TG2-IgA (Celikey, Phadia $\mathrm{GmbH}$, Freiburg, Germany) using an enzyme-linked immunosorbent assay (ELISA) with a positivity cut-off at $5 \mathrm{U} / \mathrm{ml}$, as recommended by the product manufacturer.

\section{Endoscopy and biopsies}

Upper gastrointestinal endoscopy with small-bowel mucosal biopsies was recommended for all subjects with positive POCT or EMA tests. During endoscopy, up to 5 duodenal mucosal specimens were taken. The biopsy specimens were fixed in formalin, embedded in paraffin, cut, stained with haematoxylin-eosin and scored by pathologists ( $\mathrm{AE}$ and FV) according to the Marsh-Oberhuber classification (Marsh 0, 1, 2, 3a, 3b, or 3c) $[29,30]$.

\section{Ethics approval}

The study was approved by the Ethical Committee of the University and Pharmacy "Carol Davila" and Ethical Committee of the Institute for Mother and Child Care "Alfred Rusescu" Bucharest, Romania. The antibodypositive subjects or their parents gave written informed consent for upper gastrointestinal endoscopy. 


\section{Results}

In total, 12 out of 148 (8\%) first-degree healthy relatives showed positivity in the POCT. All POCT-positive subjects proved to be EMA-positive, giving 100\% specificity for the POCT against the reference standard for serum CD autoantibody [24]. Only one more positive subject was found by the EMA test (Table 1) and all the remaining 135 healthy first-degree relatives were negative both in the POCT and for EMA.

Altogether 10/13 antibody positive family members were adults (median age 38.5 years). Four subjects positive for both POCT and EMA were negative for TG2IgA when using the manufacturer's positivity cut-off of $5 \mathrm{U} / \mathrm{ml}$. When again using $3 \mathrm{U} / \mathrm{ml}$ as cut-off, as suggested by the new ESPGHAN 2012 criteria [24], only one EMA-positive subject would have been missed by the ELISA method. Her EMA titre was low, 1:5, but she was also POCT-positive (case 4 in Table 1). The only EMApositive subject, case 7 in Table 1, with a low serum titer of 1:50 and yielding a negative test result in POCT, had a TG2-IgA titer of $4.2 \mathrm{U} / \mathrm{ml}$.

Ten of the thirteen antibody-positive first-degree relatives agreed to undergo upper gastrointestinal endoscopy and duodenal biopsies. All but one showed coeliac-type mucosal lesions of grade Marsh $2(\mathrm{n}=3)$ and Marsh 3 $(n=6)$, as summarized in Table 1. POCT was found to be positive in eight of the nine subjects with biopsyproven $\mathrm{CD}$. The three POCT-positive subjects not agreeing to undergo endoscopy also showed marked positivity

\begin{tabular}{|c|c|c|c|c|c|c|}
\hline $\begin{array}{l}\text { Case } \\
\text { no. }\end{array}$ & Gender & $\begin{array}{l}\text { Age at CD } \\
\text { antibody } \\
\text { evaluation } \\
\text { (years) }\end{array}$ & POCT & $\begin{array}{l}\text { EMA-IgA } \\
\text { (serum } \\
\text { dilution } \\
\text { step) }\end{array}$ & $\begin{array}{l}\text { TG2- } \\
\text { lgA } \\
(\mathrm{U} / \mathrm{ml})\end{array}$ & $\begin{array}{c}\text { Biopsy } \\
\text { outcome } \\
\text { (Marsh } \\
\text { classification) }\end{array}$ \\
\hline 1 & $\mathrm{~F}$ & 39 & + & $1: 4000$ & 821.5 & $3 c$ \\
\hline 2 & F & 38 & + & $1: 200$ & 37.4 & NA \\
\hline 3 & $F$ & 36 & + & $1: 1000$ & 61.8 & NA \\
\hline 4 & $F$ & 34 & + & $1: 5$ & 2.3 & $3 b$ \\
\hline 5 & $\mathrm{~F}$ & 40 & + & $1: 2000$ & 499.4 & NA \\
\hline 6 & $\mathrm{~F}$ & 42 & + & $1: 200$ & 25.6 & 1 \\
\hline 7 & $F$ & 56 & - & $1: 50$ & 4.2 & 2 \\
\hline 8 & $\mathrm{~F}$ & 2.4 & + & $1: 50$ & 3.4 & $3 a$ \\
\hline 9 & M & 10.7 & + & $1: 5$ & 3.5 & 2 \\
\hline 10 & $\mathrm{~F}$ & 36 & + & $1: 50$ & 4.0 & $3 a$ \\
\hline 11 & $F$ & 46 & + & $1: 4000$ & 40.2 & $3 c$ \\
\hline 12 & $\mathrm{~F}$ & 31 & + & $1: 200$ & 21.4 & 2 \\
\hline 13 & $\mathrm{~F}$ & 2 & + & $1: 1000$ & 72.8 & $3 c$ \\
\hline
\end{tabular}

Abbreviations: $F$ female, $M$ male, NA not available, POCT point of care test, $E M A$ antiendomysial antibody, TG2-IgA IgA class transglutaminase 2 antibodies. in both EMA and TG2-IgA tests (Table 1). The prevalence of coeliac gluten sensitivity was $8.7 \%$ as determined by positive autoantibodies.

\section{Discussion}

The present study emphasizes the usefulness of a simple rapid fingertip whole blood POCT for a presumptive diagnosis of $\mathrm{CD}$. The test was able to select correctly individuals, even clinically silent ones, for further confirmatory diagnostic studies such as duodenal biopsies. We show that the POCT tested on site worked hand in hand with the centralized laboratory golden standard CD autoantibody testing, the EMA test [24]; among 148 tested subjects there was only one discrepant result, a POCT-negative person who had a low serum EMA titer but who was also negative for TG2-IgA (case No. 7 in Table 1). Furthermore, gluten-induced small intestinal mucosal lesion, i.e. Marsh class 2 and 3, was detected in all but one of the biopsied subjects. From this series of individuals we also noted that even low titers of EMA positivity may be indicative of mucosal injury.

To confirm or disprove our hypothesis that the used POCT biomarker is able to pick out CD also in adults, we chose to study first-degree family members of $\mathrm{CD}$ patients. In fact, $77 \%$ of the family members positive for the test were adults and our results are in agreement with those previously obtained in children $[21,27,28]$. The present POCT results also confirm the results of a recent report where POCT was shown to have a pooled sensitivity of $96.4 \%$ and pooled specificity of $97.7 \%$ for detection of $\mathrm{CD}$ [26]. The same report showed the centralized hospital ELISA TG2-IgA in 11/15 studies to have a sensitivity of $>90 \%$ and in $13 / 15$ studies a specificity of $>90 \%$. ELISA testing for the presence of TG2-IgA seems to lead to false-positive results especially in individuals carrying a high risk of $\mathrm{CD}$ such as relatives of patients [31]. As reviewed by Husby et al. [24], TG2IgA positivity without $\mathrm{CD}$ is also seen in autoimmune disorders, in patients with infections, tumors, psoriasis and heart and liver diseases. The epitopes in TG2 for the false-positive antibodies in other diseases and seen in ELISA tests differ from the TG2 epitopes which CD patient autoantibodies target. Further, positive TG2-IgA ELISA results in patients without $C D$ do not correlate with the EMA results [32].

On-site use of the POCT seems to provide a strong tool for the health care system in case-finding of CD. This offers immediate results and potentially shortens the diagnostic process in adults [17-19]. Moreover, the use of a POCT in primary care might lower the costs related to equipment, trained personnel and time-management of centralized serological tests. As of now, a small-intestinal biopsy is still needed for confirmation of diagnosis. But on the other hand, the present study 
results support the new global guidelines on $\mathrm{CD}$ stating that TG2-IgA can be assessed in the physician's office by using the self antibody-based rapid finger-tip test, and in areas with limited resources a rapid test may be used as sole diagnostic means for CD [33].

A limitation in the present study is the relatively small population studied. The study should be repeated in larger adult patient populations in primary care and specialized outpatient clinics dealing with patients with vague and various symptoms or signs where $C D$ could be the underlying cause of ill health.

The serologic prevalence of $\mathrm{CD}$ in our study in Romania was $8.7 \%$, similar to that reported in other family studies [13-15]. The present results argue, similarly to a recent case-finding study in type 1 diabetes [27], that the $\mathrm{CD}$ prevalence in Romania is probably much higher than previously thought. In fact, there has previously been an indication that the disease exists in adults in Romania, unspecific symptoms have shown a frequent smallintestinal mucosal injury indicative of CD [34]. Overall, the POCT seems to work as well as the EMA test in case identification [14]. A recent Austrian study indicates that the POCT is a reliable, easy to use and well-accepted tool even for home testing of first- and second-degree relatives of patients with $\mathrm{CD}$ [35].

\section{Conclusion}

In conclusion, case-finding in the primary care using a fingertip whole blood on site POCT could be the way forward in the early detection and diagnosis of celiac disease.

\section{Abbreviations \\ CD: Coeliac disease; POCT: Point-of-care test; EMA: Endomysial antibodies; TG2-IgA: Transglutaminase 2 antibodies; HLA: Human leukocyte antigen; ELISA: Enzyme-linked immunosorbent assay.}

\section{Competing interests}

Ani Biotech, who donated the point of care test kits, did not take part in designing or executing the study, were not involved in reading the results or in writing the manuscript. MM is one inventor of the patent "Methods and Means for Detecting Gluten-Induced Diseases", USA States Patent Number 7,361,480 - USA, Patent Granted 22.4.2008; European Patent No. 1390753, European Patent Office 22.10.2008. Finn Medi Oy Ltd, owned by the University of Tampere and Tampere University Hospital, Finland, has commercialized the innovation and licensed it to Ani Biotech, which used it to develop the Biocard Celiac Test. Finn Medi and Ani Biotech were not involved in the study. The other authors declare no competing interests.

\section{Authors' contributions}

AP contributed to the conception and design, supervised all aspects of the evaluation, carried out the collection and analysis of data, wrote the initial version of the manuscript and approved the final manuscript as submitted. MJ provided supervision in all aspects of the evaluations, including design, clinical examination, endoscopic biopsies critically revised the manuscript and approved the final version as submitted. CJ contributed to the literature search and analysis of data, clinical management of adult participants, critically revised the manuscript and approved the final version as submitted. VB made a substantial contribution to data collection and analysis, assisted with the initial manuscript preparation and approved the final version as submitted. CB made a substantial contribution to all aspects of evaluation, including clinical examination and management of pediatric participants, acquisition and analysis of data, revised the manuscript and approved the final text as submitted. AE and FV made a contribution on the interpretation of data, provided histological interpretation of the mucosal biopsies, critically revised the manuscript and approved the final text as submitted. KL contributed substantially to the data results, revised the manuscript and approved the final version as submitted. IA contributed substantially to the design and interpretation of data, critically revised the manuscript for important intellectual content and approved the final manuscript as submitted. MM is the senior author and expert in the field; he was responsible for the conception, design and the interpretation of data, contributed to obtaining of funding, made a substantial contribution to the manuscript preparation, including review, critique and advice on each version of the manuscript, directed the literature search and approved the final version of the manuscript as submitted.

\section{Acknowledgments}

This study was supported by grants of the Romanian National Authority for Scientific Research CNDI-UEFISCDI projects number 1/2005 and 111/2012 (AP) and the Competitive State Research Financing of the Expert Responsibility Area of Tampere University Hospital, Tampere, Finland (MM). Ani Biotech Oy Ltd, Vantaa, Finland, donated the point of care test kits to AP at the Institute for Mother and Child Care "Alfred Rusescu", Bucharest, Romania, for academic research.

\section{Author details}

'University of Medicine and Pharmacy "Carol Davila", Str. Dionisie Lupu nr. 37, sector 1, 020022 Bucharest, Romania. Institute for Mother and Child Care "Alfred Rusescu", Bdv. Lacul Tei nr. 120, sector 2, 020395 Bucharest, Romania. ${ }^{3}$ Central University Emergency Military Hospital "Dr. Carol Davila", Str. Mircea Vulcanescu nr. 88, sector 1, 010825 Bucharest, Romania. ${ }^{4}$ Tampere Center for Child Health Research, University of Tampere and Tampere University Hospital, Finn-Medi 3, Biokatu 10, 33520 Tampere, Finland.

Received: 17 February 2013 Accepted: 9 July 2013

Published: 12 July 2013

\section{References}

1. Fasano A, Catassi C: Celiac disease. N Engl J Med 2012, 367:2419-2426

2. Rubio-Tapia A, Ludvigsson JF, Brantner TL, Murray JA, Everhart JE: The prevalence of celiac disease in the United States. Am J Gastroenterol 2012, 107:1538-1544.

3. Mäki M, Mustalahti K, Kokkonen J, Kulmala P, Haapalahti M, Karttunen T, Ilonen J, Laurila K, Dahlbom I, Hansson T, Höpfl P, Knip M: Prevalence of celiac disease among children in Finland. N Engl J Med 2003, 348:2517-2524.

4. Mustalahti K, Catassi C, Reunanen A, Fabiani E, Heier M, McMillan S, Murray L, Metzger MH, Gasparin M, Bravi E, Mäki M: The prevalence of celiac disease in Europe: results of a centralized, international mass screening project. Ann Med 2010, 43:587-595.

5. Bach JF: The effect of infections on susceptibility to autoimmune and allergic diseases. N Engl J Med 2002, 347:911-920.

6. Lohi S, Mustalahti K, Kaukinen K, Laurila K, Collin P, Rissanen H, Lohi O, Bravi E, Gasparin M, Reunanen A, Mäki M: Increasing prevalence of coeliac disease over time. Aliment Pharmacol Ther 2007, 26:1217-1225.

7. Rubio-Tapia A, Kyle RA, Kaplan EL, Johnson DR, Page W, Erdtmann F, Brantner TL, Kim WR, Phelps TK, Lahr BD, Zinsmeister AR, Melton LJ 3rd, Murray JA: Increased prevalence and mortality in undiagnosed celiac disease. Gastroenterology 2009, 137:88-93.

8. Catassi C, Kryszak D, Bhatti B, Sturgeon C, Helzlsouer K, Clipp SL, Gelfond D, Puppa E, Sferruzza A, Fasano A: Natural history of celiac disease autoimmunity in a USA cohort followed since 1974. Ann Med 2010, 42:530-538.

9. Freeman HJ: Adult celiac disease in the elderly. World J Gastroenterol 2008, 14:6911-6914

10. Vilppula A, Kaukinen K, Luostarinen L, Krekelä I, Patrikainen H, Valve R, Mäki M, Collin P: Increasing prevalence and high incidence of celiac disease in elderly people: a population-based study. BMC Gastroenterol 2009, 9:49.

11. Sapone A, Bai JC, Ciacci C, Dolinsek J, Green PH, Hadjivassiliou M, Kaukinen K, Rostami K, Sanders DS, Schumann M, Ullrich R, Villalta D, Volta U, Catassi C, 
Fasano A: Spectrum of gluten-related disorders: consensus on new nomenclature and classification. BMC Med 2012, 10:13.

12. Mäki M: Lack of consensus regarding definitions of coeliac disease. Nat Rev Gastroenterol Hepatol 2012, 9:305-306.

13. MacDonald WC, Dobbins WO 3rd, Rubin CE: Studies of the familial nature of celiac sprue using biopsy of the small intestine. N Engl J Med 1965, 272:448-456.

14. Mäki M, Holm K, Lipsanen V, Hällström O, Viander M, Collin P, Savilahti E, Koskimies S: Serological markers and HLA genes among healthy firstdegree relatives of patients with coeliac disease. Lancet 1991, 338:1350-1353.

15. Doğan Y, Yildirmaz S, Ozercan IH: Prevalence of celiac disease among first-degree relatives of patients with celiac disease. J Pediatr Gastroenterol Nutr 2012, 55:205-208.

16. Hin H, Bird G, Fisher P, Mahy N, Jewell D: Coeliac disease in primary care: case finding study. Br Med J 1999, 318:164-167.

17. Green PHR, Stavropoulos SN, Panagi SG, Goldstein SL, Mcmahon DJ, Absan H, Neugut Al: Characteristics of adult celiac disease in the USA: results of a national survey. Am J Gastroenterol 2001, 96:126-131.

18. Gray AM, Papanicolas IN: Impact of symptoms on quality of life before and after diagnosis of coeliac disease: results from a UK population survey. BMC Health Serv Res 2010, 10:105.

19. Norström F, Lindholm L, Sandström O, Nordyke K, Ivarsson A: Delay to celiac disease diagnosis and its implications for health-related quality of life. BMC Gastroenterol 2011, 11:118

20. Mustalahti K, Collin P, Sievänen H, Salmi J, Mäki M: Osteopenia in patients with clinically silent coeliac disease warrants screening. Lancet 1999, 354:744-745.

21. Korponay-Szabó IR, Szabados K, Pusztai J, Uhrin K, Ludmány E, Nemes E, Kaukinen K, Kapitány A, Koskinen L, Sipka S, Imre A, Mäki M: Population screening for coeliac disease in primary care by district nurses using a rapid antibody test: diagnostic accuracy and feasibility study. Br Med J 2007, 335:1244-1247.

22. Vilppula A, Kaukinen K, Luostarinen L, Krekelä I, Patrikainen H, Valve R, Luostarinen M, Laurila K, Mäki M, Collin P: Clinical benefit of gluten-free diet in screen-detected older celiac disease patients. BMC Gastroenterol 2011, 11:136.

23. Johnston SD, Watson RG, McMillan SA, Sloan J, Love AH: Coeliac disease detected by screening is not silent - simply unrecognized. QJM 1998, 91:853-860.

24. Husby S, Koletzko S, Korponay-Szabo IR, Mearin ML, Phillips A, Shamir R, Troncone R, Giersiepen K, Branski D, Catassi C, Lelgeman M, Mäki M, Ribes-Koninck C, Ventura A, Zimmer KP, for the ESPGHAN Working Group on Coeliac Disease Diagnosis, on behalf of the ESPGHAN Gastroenterology Committee: European Society for Pediatric Gastroenteorlogy, Hepatology, and Nutrition Guidelines for the diagnosis of coeliac disease. J Pediatr Gatroenterol Nutr 2012, 54:136-160.

25. Sulkanen S, Halttunen T, Laurila K, Kolho KL, Korponay-Szabó IR, Sarnesto A, Savilahti E, Collin P, Mäki M: Tissue transglutaminase autoantibody enzyme-linked immunosorbent assay in detecting celiac disease. Gastroenterology 1998, 115:1322-1328.

26. Giersiepen K, Lelgemann M, Stuhldreher N, Ronfani L, Husby S, Koletzko S, Korponay-Szabó IR: Accuracy of diagnostic antibody tests for coeliac disease in children: summary of an evidence report. $J$ Pediatr Gastroenterol Nutr 2012, 54:229-241.

27. Popp A, Mihu M, Munteanu M, Ene A, Dutescu M, Colcer F, Raducanu D, Laurila K, Anca I, Mäki M: Prospective antibody case finding of coeliac disease in type-1 diabetes children. Need of biopsy revisited. Acta Paediatr. in press.

28. Raivio T, Kaukinen $\mathrm{K}$, Nemes E, Laurila K, Collin P, Kovács JB, Mäki M, Korponay-Szabó IR: Self transglutaminase-based rapid celiac disease antibody detection by a lateral flow method. Aliment Pharmacol Ther 2006, 24:147-154.

29. Marsh MN: Grains of truth: evolutionary changes in small intestinal mucosa in response to environmental antigen challenge. Gut 1990, 31:111-114.

30. Oberhuber G, Granditsch G, Volgelsang H: The histopathology of celiac disease: time for a standardized report scheme for pathologists. Eur I Gastroenterol Hepatol 1999, 11:1185-1194.
31. Vecsei A, Arenz T, Heilig G, Arenz S, Bufler P, Koletzko S: Influence of age and genetic risk on anti-tissue transglutaminase IgA titers. J Pediatr Gastroenterol Nutr 2009, 48:544-549.

32. Simon-Vecsei Z, Király R, Bagossi P, Tóth B, Dahlbom I, Caja S, Csősz E, Lindfors K, Sblattero D, Nemes E, Mäki M, Fésüs L, Korponay-Szabó l: A single conformational transglutaminase 2 epitope contributed by three domains is critical for celiac antibody binding and effects. Proc Natl Acad Sci USA 2012, 109:431-436.

33. Bai JC, Fried M, Corazza GR, Schuppan D, Farthing M, Catassi C, Greco L, Cohen H, Ciacci C, Eliakim R, Fasano A, González A, Krabshuis JH, LeMair A: World Gastroenterology Organisation global guidelines on celiac disease. J Clin Gastroenterol 2013, 47:121-126.

34. Dobru D, Pascu O, Tantău M, Gheorghe C, Goldiş A, Bălan G, Olteanu I, Fraticiu A, Dumitru E, Miuțescu E, Mulder C, Podoleanu S: The prevalence of celiac disease at endoscopy units in Romania: routine biopsies during gastroscopy are mandatory (a multicenter study). Rom J Gastroenterol 2003, 12:97-100

35. Pichler J, Zilbauer M, Torrente F, Heuschkel R, Phillips A, Salvestrini C: Feasibility of a finger prick-based self-testing kit in first- and second-degree relatives of children with coeliac disease. World J Gastroenterol 2011, 17:1840-1843.

\section{doi:10.1186/1471-230X-13-115}

Cite this article as: Popp et al.: Fingertip rapid point-of-care test in adult case-finding in coeliac disease. BMC Gastroenterology 2013 13:115.

\section{Submit your next manuscript to BioMed Central and take full advantage of:}

- Convenient online submission

- Thorough peer review

- No space constraints or color figure charges

- Immediate publication on acceptance

- Inclusion in PubMed, CAS, Scopus and Google Scholar

- Research which is freely available for redistribution 